\title{
Development of low calorie RTS beverage rich in nutraceuticals and antioxidants from cactus fruit and kokum fruit by blending with coconut water
}

Vasundhra Devidas More, Sindhu, Shweta Saloni, Sujata and Vipul Jaglan

Received : $10.04 .2018 ;$ Accepted : 13.04 .2018

See end of the Paper for authors' affiliation

Correspondence to :

Vasundhra Devidas More Department of Food Technology, Vignan's Foundation for Science, Technology and Research University, Vadlamudi, Guntur (A.P.) India
- Abstract : Cactus fruit (Prickly pear) has received abundant attention with regard to its high nutraceutical value and also is also grown locally in various regions of Maharashtra. Therefore, the present study was carried out on preparation of RTS beverage blends from prickly pear, kokum and coconut water to improve its quality and flavor. These blends were packaged in $200 \mathrm{ml}$ nontransparent stand pouch and tested for physico-chemical, sensory evaluation and microbial analysis. Chemical composition carried out of unblended pulp. The $\mathrm{pH}$, total soluble solids (TSS), titratable acidity, color analysis, ascorbic acid were determined. The blend of cactus fruit and kokum at ratio (3:1) received the highest scores in overall acceptability. Therefore, it was evaluated for polyphenol content by using Folin-Ciocalteu reagent, antioxidant activity was measured using two in vitro assays 2, 2'-diphenyl-1-picrylhydrazyl (DPPH) and sensory was carried out to check the acceptability of beverage after adding of low GI sugar and stevia. Pasteurization was carried out to increase shelf life.

- Key words : Low calorie, RTS beverage, Antioxidants, Nutraceuticals, Cactus, Kokum

- How to cite this paper : More, Vasundhra Devidas, Sindhu, Saloni, Shweta, Sujata and Jaglan, Vipul (2018). Development of low calorie RTS beverage rich in nutraceuticals and antioxidants from cactus fruit and kokum fruit by blending with coconut water. Internat. J. Agric. Engg., 11(Sp. Issue) : 22-28, DOI: 10.15740/HAS/IJAE/11.Sp. Issue/22-28. 